\title{
CRENÇAS E ATITUDES LINGUÍSTICAS QUANTO AO USO DOS PRONOMES NÓS E A GENTE NA CIDADE DE MACEIÓ/AL
}

Elyne Giselle de Santana Lima Aguiar Vitório

(UFAL)

\section{RESUMO}

Tendo em vista que a maneira como se avaliam as formas linguísticas - positiva ou negativamente - pode acelerar ou barrar uma mudança na língua, focalizamos, neste trabalho, o problema de avaliação linguística (LABOV, 1972), com o intuito de mensurar as normas subjetivas dos falantes maceioenses em relação à alternância pronominal nós e a gente e à concordância verbal relacionada a essas formas pronominais. Para tanto, recorremos aos pressupostos teórico-metodológicos da Teoria da Variação e Mudança Linguística (LABOV, 1972) e utilizamos uma amostra constituída de 52 entrevistas de falantes maceioenses. De acordo com os dados analisados, verificamos que, em relação à alternância pronominal, as crenças e atitudes linguísticas dos falantes não coadunam com o comportamento linguístico da comunidade, sugerindo que tal alternância é um fenômeno linguístico do tipo marcador, e, no que diz respeito à concordância verbal, verificamos que as crenças e atitudes linguísticas dos falantes caminham na mesma direção do comportamento linguístico da comunidade, sugerindo que tanto a concordância com nós quanto a concordância com a gente são fenômenos do tipo estereótipo, com uma aceitação maior do uso da variante nós $+3 P S$.

PALAVRAS-CHAVE: Nós e a gente. Alternância pronominal;. Concordância verbal. Avaliação social. 


\section{1 lntrodução}

A alternância pronominal nós e a gente, representando a primeira pessoa do plural, nas variedades brasileiras, tem sido objeto de estudos sistemáticos, que mostram que a variação nós e a gente pode ser caracterizada como um processo de mudança, no qual, gradativamente, a gente substitui o pronome nós. Encaixado no sistema linguístico do português brasileiro, a gente não só tem ocupado o espaço de nós para a referência à primeira pessoa do plural na posição de sujeito, como também começa a se implementar nas funções de complemento e adjunto (VIANNA; LOPES, 2012; 2015; RUBIO, 2014; SANTOS, 2014; VITÓRIO, 2016b).

Outro ponto a destacar diz respeito à concordância verbal estabelecida com essas formas pronominais. Embora as gramáticas normativas ainda considerem a concordância verbal como uma regra categórica, estudos sociolinguísticos mostram que, nas variedades brasileiras, há um comportamento variável de aplicação da regra de concordância verbal (ZILLES; MAYA; SILVA, 2000; RUBIO; GONÇALVES, 2012; BRANDÃO, 2016; CARMO, 2016). Assim, a concordância verbal estabelecida com os pronome nós e a gente pode ocorrer tanto com o morfema de primeira pessoa do plural (doravante 1PP) quanto com o morfema de terceira pessoa do singular (doravante 3PS).

É importante também considerar o valor social associado a essas formas variantes. Labov (1972) reconhece que há julgamentos sociais conscientes e inconscientes sobre a língua, o que significa dizer que, embora apresentem o mesmo valor de verdade ou representacional, as variantes linguísticas tendem a diferir quanto às avaliações ou valorações sociais, podendo, assim, serem consideradas como: estereótipo - traço linguístico socialmente marcado de forma consciente; marcador - traço linguístico social e estilisticamente marcado; e indicador - traço linguístico socialmente marcado, mas não sujeito à variação estilística.

Em relação à variação nós e a gente, Zilles (2007) destaca que o uso de a gente, na língua falada, não é estigmatizado. Freitag et al (2016) também mostram que a gente é uma variante linguística caracterizada como marcador, ou seja, é um traço linguístico social e estilisticamente marcado. No que diz respeito à concordância verbal relacionada ao uso desses pronomes, estudos sociolinguísticos apontam para uma avaliação social estigmatizada para o uso de nós $+3 P S$ e a gente $+1 P P$, sendo essas ocorrências associadas a falantes menos escolarizados (NARO; GORSKI; FERNANDES, 1999; RUBIO; GONÇALVES, 2012). 
Tendo em vista que a avaliação linguística é um aspecto social relevante da variação e da mudança linguística (LABOV, 1972), pois o prestígio ou o estigma que uma comunidade de fala associa a uma determinada forma variante pode acelerar ou barrar uma mudança na língua, analisamos, neste estudo, as crenças e atitudes linguísticas sobre o uso das formas pronominais nós e a gente na cidade de Maceió/AL, ou seja, procuramos mensurar as normas subjetivas dos falantes maceioenses em relação à alternância pronominal nós e $a$ gente na posição de sujeito e à concordância verbal relacionada a essas formas pronominais.

Para tanto, consideramos não só que, apesar do alto percentual do pronome inovador nas variedades brasileiras (VIANNA; LOPES, 2015), principalmente na fala maceioense (VITÓRIO, 2015a,b, 2016a,b), os falantes pensam utilizar mais o pronome nós (FREITAG, 2016a), principalmente em contextos mais formais, o que nos leva à hipótese de marcadores linguísticos, como também que as variantes nós $+1 P P$ e a gente + $3 P S$ são as formas preferidas, sendo as variantes nós $+3 P S$ e a gente + $1 P P$ as formas vistas como "desvios" da norma e, dessa forma, entendidas como traços linguísticos socialmente marcados.

A fim de cumprir os propósitos enunciados, nosso texto está organizado da seguinte forma: na próxima seção, apresentamos o que os estudos sociolinguísticos têm mostrado sobre a realização dos pronomes nós e a gente em diversas variedades brasileiras; em seguida, apresentamos os pressupostos teórico-metodológicos que orientaram o desenvolvimento desta pesquisa; na seção seguinte, focalizamos nas discussões dos dados obtidos tanto para a alternância nós e a gente na posição de sujeito quanto para a concordância verbal relacionada a essas formas pronominais; por fim, tecemos nossas considerações finais.

\section{Sobre a variação nós e a gente no português brasileiro}

Dentre os temas de investigação das pesquisas sociolinguísticas no Brasil, a variação no uso pronominal de primeira pessoa do plural é um dos mais estudados. Tal interesse tem mostrado que, de maneira geral, na língua falada, o pronome inovador a gente é a variante preferida, como observamos no gráfico 1 , sendo essa variação caracterizada como um processo de mudança, condicionada por restrições linguísticas e extralinguísticas. Vianna e Lopes (2015) não só indicam um comportamento semelhante nas capitais investigadas, como também destacam a relevância das 
variáveis paralelismo formal, traço semântico do referente, tempo verbal, saliência fônica, faixa etária, sexo, escolaridade e localidade.

Gráfico 1: Realizações de nós e a gente na posição de sujeito no português brasileiro

\section{$\square$ nós $\square$ a gente}
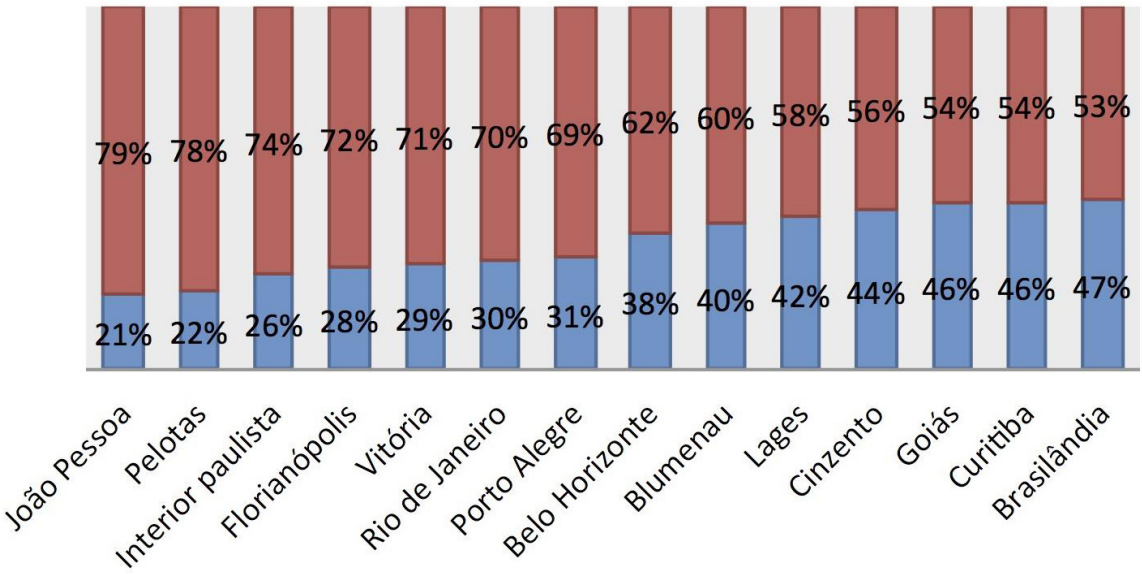

Fonte: Adaptado de Lopes (2012) e Rubio (2014)

Na comunidade de fala maceioense, verificamos, conforme gráfico 2 , que tanto na fala infantil quanto na fala adulta, a gente é a variante preferida para representar a primeira pessoa do plural, apresentando, respectivamente, percentuais de $83 \%$ e $84 \%$. Entre os falantes que possuem o ensino superior completo, a gente também apresenta um alto percentual de realização - $80 \%$ versus $20 \%$ de nós. O alto percentual de uso a gente na fala causa efeitos na escrita, fazendo emergir, na escrita escolar, uma variante linguística não prescrita nos manuais normativos, mas consagrada pelo uso linguístico, apresentando, assim, um percentual de $14 \%$. 
Gráfico 2: Percentual de nós e a gente na posição de sujeito na cidade de Maceió

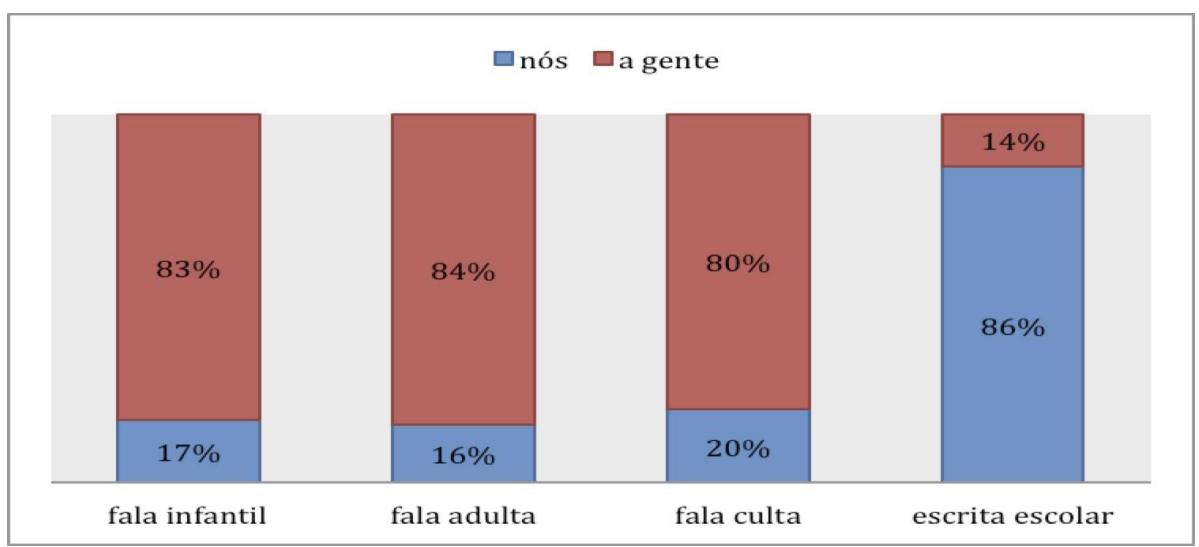

Fonte: Adaptado de Vitório (2015a,b, 2016a,b)

Em relação à variação da concordância verbal com os pronomes nós e a gente, pesquisas sociolinguísticas não só destacam a relevância de restrições linguísticas e sociais, a saber, explicitude do sujeito, saliência fônica, paralelismo discursivo, grau de determinação do sujeito, tempo e modo verbal, escolaridade, sexo/gênero, faixa etária e localidade, como também mostram, de acordo com os gráficos 3 e 4, que enquanto a realização das variantes nós $+1 P P$ e nós $+3 P S$ tende a ser mais variável a depender da comunidade, com percentuais maiores ou menores de emprego das formas verbais de 1PP, a variação a gente $+1 P P$ e a gente + $3 P S$ parece ser um fenômeno não amplamente variável nas comunidades estudadas, tendo em vista a alta preferência pela realização da variante $a$ gente $+3 P S$. 
Gráfico 3: Percentuais de nós $+1 P P$ e nós $+3 P S$ nas variedades brasileiras

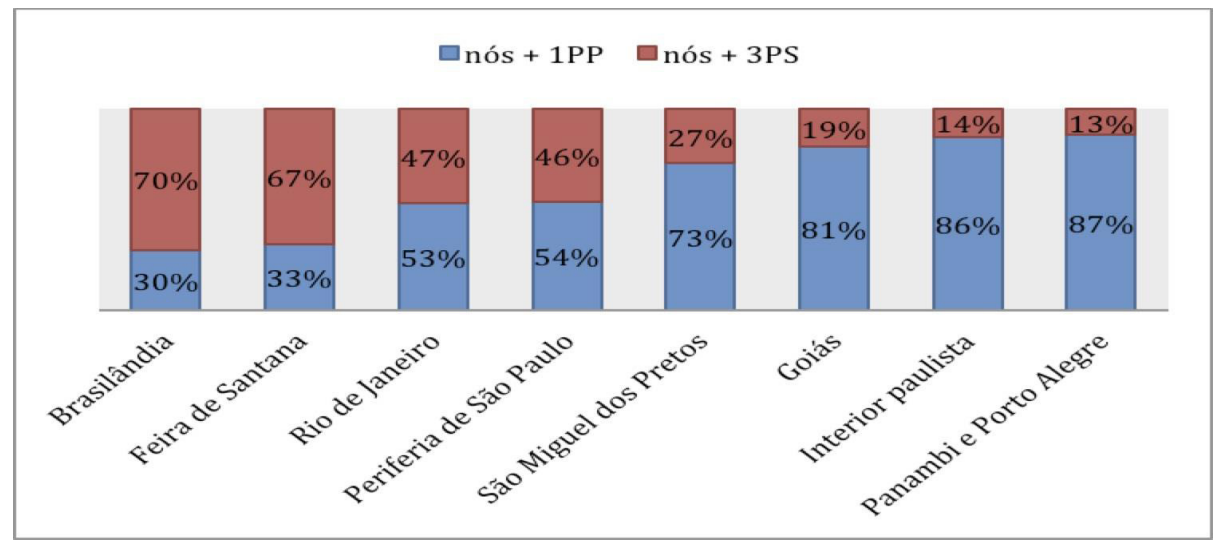

Fonte: Adaptado de Rubio (2014)

Gráfico 4: Percentuais de a gente $+1 P P$ e a gente $+3 P S$ nas variedades brasileras

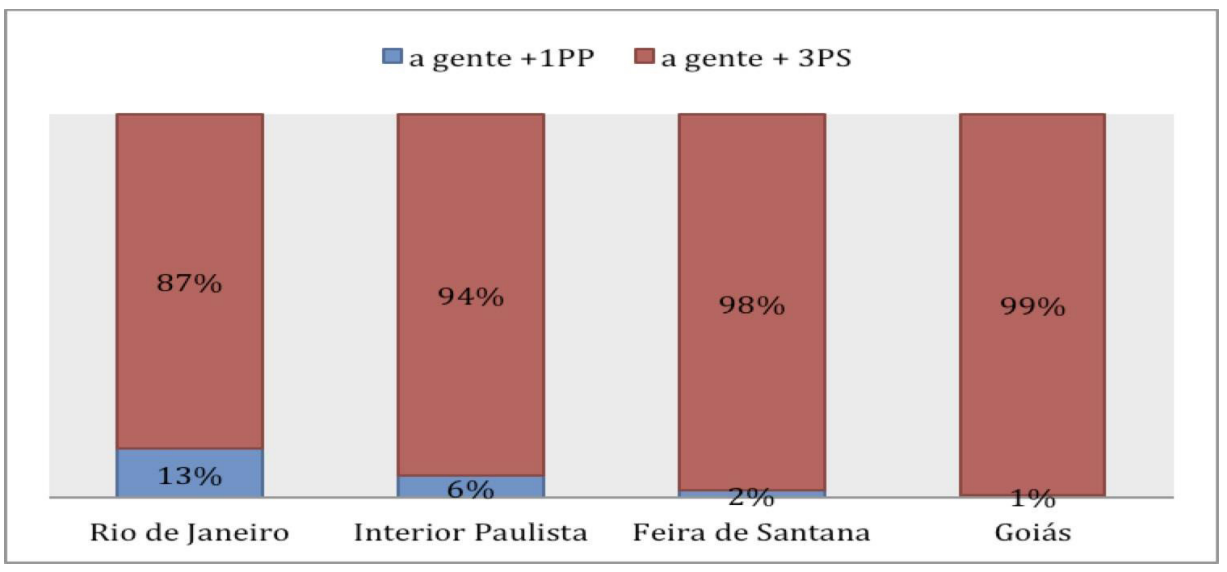

Fonte: Adaptado de Rubio (2014) 
$\mathrm{Na}$ comunidade de fala maceioense, verificamos, conforme gráfico 5 , que a concordância verbal com nós seleciona a variante nós $+1 P P$, mas nós + 3PS apresenta um percentual de $22 \%$ na fala infantil, $4 \%$ na fala adulta e ocorre, na escrita escolar, com um percentual de $11 \%$. Em relação à concordância com a gente, verificamos, conforme gráfico 6 , que tanto na fala infantil quanto na fala adulta, a gente $+3 P S$ é a variante preferida, apresentando, respectivamente, percentuais de $99 \%$ e $94 \%$, mas, na escrita escolar, a gente $+1 P P$ é a forma selecionada, apresentando, assim, um percentual de $62 \%$, o que é entendido pela autora como um caso de hipercorreção na língua escrita (cf. VITÓRIO, 2015b).

Gráfico 5: Percentuais de nós $+1 P P$ e nós $+3 P S$ na cidade de Maceió

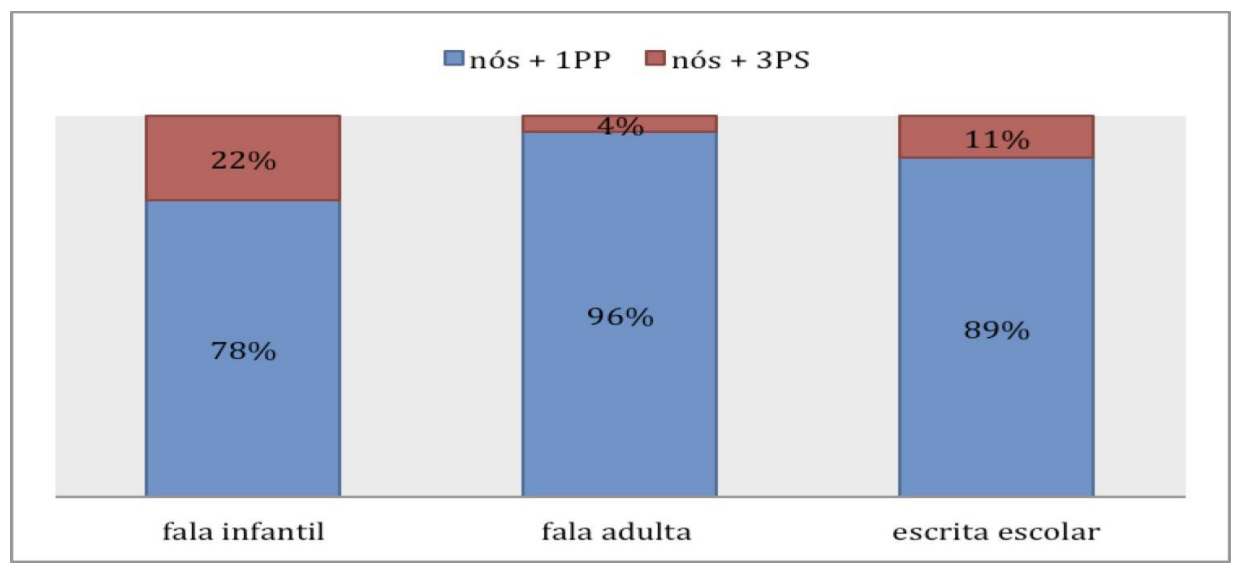

Fonte: Adaptado de Vitório (2015a,b, 2016b) 
Gráfico 6: Percentuais de a gente $+1 P P$ e a gente $+3 P S$ na cidade de Maceió

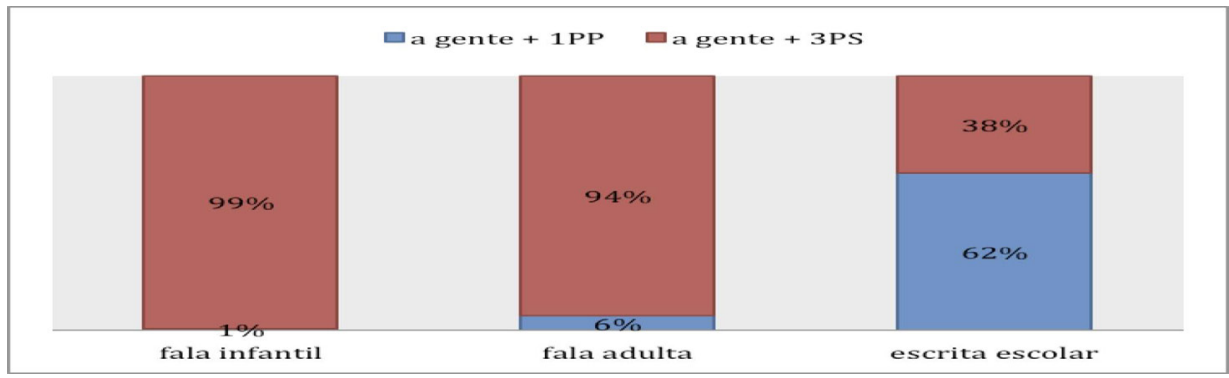

Fnte: Adaptado de Vitório (2015a,b, 2016b)

Esses dados mostram que, na cidade de Maceió, a gente é o pronome selecionado para representar a primeira pessoa do plural e que a concordância verbal com os pronomes nós e $a$ gente tanto pode ocorrer com o verbo na 1PP quanto na 3PS, com a preferência pelo uso de nós $+1 P P \mathrm{e}$ a gente $+3 P S$. Resta-nos analisar como os falantes maceioenses avaliam não só a alternância pronominal nós e a gente na posição de sujeito, como também a concordância verbal estabelecida com essas formas pronominais. Nosso objetivo é verificar se a avaliação social vai na mesma direção do comportamento linguístico realizado pelos falantes.

\section{Aporte teórico-metodológico}

Para o desenvolvimento deste estudo, recorremos à proposta teórico-metodológica da Teoria da Variação e Mudança Linguística (LABOV, 1972). Tal proposta faz da variação linguística seu objeto de estudo e análise, passando toda a língua a apresentar variação, que é potencialmente um desencadeador de mudança, o que significa considerar não só que não há comunidade linguística ou grupo social que use a língua homogeneamente, como também não há falante de estilo único. A língua é um sistema inerentemente variável, logo a competência linguística do falante é constituída por regras categóricas e regras variáveis.

A solução, argumentaremos, se encontra no rompimento da identificação de estruturalidade [structuredness] com homogeneidade. A chave para uma concepção racional da mudança linguística - e mais, da 
própria língua - é a própria língua - é a possibilidade de descrever a diferenciação ordenada numa língua que serve a uma comunidade. Argumentaremos que o domínio de uma falante nativo [nativelike command] de estruturas heterogêneas não tem a ver com multidialetalismo nem mesmo com "mero" desempenho, mas é parte da competência linguística monolíngue. Um dos corolários de nossa abordagem é que numa língua que serve a uma comunidade complexa (i.e., real), a ausência de heterogeneidade estruturada é que seria disfuncional. (WEINREICH; LABOV; HERZOG, 2006, p. 36).

Para a descrição de regras variáveis, o pesquisador sociolinguista precisa definir seu objeto de estudo, delimitar a amostra da pesquisa e constituir o corpus, transcrever, codificar e quantificar os dados e, por fim, interpretar e explicar os resultados obtidos do fenômeno linguístico variável analisado, permitindo, assim, a explanação de até cinco problemas propostos pela teoria laboviana, a saber, restrição, transição, encaixamento, avaliação e implementação das formas variantes, o que o leva a explicar o motivo de determinada comunidade de fala usar certas formas linguísticas e não outras quando faz uso da língua.

Em nosso estudo, focalizamos na análise do problema da avaliação linguística, que, segundo Labov (1972), está relacionado à forma como as variantes linguísticas são percebidas pelos membros da comunidade de fala, ou seja, visa compreender os julgamentos dos falantes em relação ao uso da língua. Esses julgamentos ocorrem através do significado social atribuído às formas variantes - prestígio ou não prestígio e estão associados à seguinte questão: como uma variante linguística é avaliada pelo falante em termos de significado social? Essa questão nos leva à discussão sobre crenças e atitudes linguísticas dos falantes.

O estudo das atitudes e das crenças linguísticas é uma das tarefas que a Sociolinguística se propõe, sendo mesmo uma das suas cinco questões fundadoras [...] e se refere ao problema da avaliação, relativo aos julgamentos subjetivos do usuário quanto à sua própria variedade linguística e à dos seus interlocutores. (CYRANKA, 2007, p. 17).

López Morales (2004) argumenta que o grande problema para a Sociolinguística é determinar até que ponto uma atitude expressa pelos falantes em relação ao uso da língua está relacionada a fenômenos linguísticos ou à valorização dos falantes de determinado grupo social. Segundo o autor, as crenças e atitudes (sócio)linguísticas dos falantes ou de uma comunidade de fala podem afetar fenômenos específicos de uma língua 
ou de uma variedade linguística e suas consequências são variadas, mas a mais grave é o estímulo à discriminação social, que exclui socialmente grupos de falantes de variedades de baixo prestígio.

Nesse contexto, mensurar crenças e atitudes linguísticas, que são entendidas, respectivamente, de acordo com López Morales (2004), como pensamento, visão, percepção, opinião, julgamento que se tem sobre o outro, sobre o mundo e sobre si mesmo e como uma reação de um determinado indivíduo perante algo ou alguma situação que presencia, sendo, portanto, a crença constituída da atitude, tem contribuído para a compreensão dos processos de variação e mudança linguística, uma vez que é possível aferir o comportamento dos indivíduos em relação à sua fala, à fala dos outros falantes e à fala de uma determinada comunidade de fala, possibilitando, assim, predizer um dado comportamento linguístico.

[...] as atitudes linguísticas influem decisivamente nos processos de variação e mudança linguísticos que se produzem nas comunidades de fala. Uma atitude favorável ou positiva pode fazer que uma mudança linguística se cumpra mais rapidamente, que em certos contextos predomine o uso de uma língua em detrimento de outra [...] que certas variantes linguísticas se confinem aos contextos menos formais e outras predominem nos estilos cuidados. Uma atitude desfavorável ou negativa pode levar ao abandono e ao esquecimento de uma língua ou impedir a difusão de uma variante ou uma mudança linguística. (MORENO FERNANDÉZ, 1998, p. 179, tradução nossa).

De acordo com Labov (1972), as crenças linguísticas de um falante ou de uma comunidade podem ser entendidas como "um conjunto uniforme de atitudes frente à linguagem que são partilhadas por quase todos os membros da comunidade de fala, seja no uso de uma forma estigmatizada ou prestigiada da língua em questão" (p. 176). Isso significa considerar, conforme pontua Kaufimann (2011, p. 122), que as pesquisas sociolinguísticas sobre crenças e atitudes linguísticas são aplicadas para "analisar fenômenos em relação ao comportamento linguístico, seja este comportamento vinculado a variantes específicas de uma variedade ou às variedades em si (por exemplo, perda ou manutenção dela)".

Mollica (2004), ao falar sobre crenças e atitudes linguísticas, destaca que esse tipo de estudo merece atenção especial e constante dos sociolinguistas, uma vez que "seus resultados oferecem desdobramentos relevantes à realidade" (p. 9). Dessa forma, a análise e a descrição dos sentimentos e comportamentos da própria fala e da fala do outro podem 
auxiliar na delimitação da função que as formas linguísticas tomam em uma determinada comunidade de fala, tendo em vista que as crenças e atitudes linguísticas são consideradas maneiras de agir e reagir em relação à linguagem, permitindo, assim, diferenciar grupos e identificar, dentro de um grupo social, os valores atribuídos às variantes linguísticas.

Estudos relacionados ao tema "Crenças e Atitudes Linguísticas" têm apontado pistas para a Sociolinguística na compreensão de questões que podem estar relacionadas a determinadas atitudes linguísticas manifestadas por um grupo ou por uma comunidade de fala. Em toda sociedade, as diferenças de "poder" existentes entre grupos sociais distintos podem ser percebidas na variação linguística e nas atitudes para com essas variações. (BOTASSINI, 2015, p. 102).

Dessa forma, focalizamos, neste trabalho, a análise da avaliação linguística dos pronomes nós e a gente na cidade de Maceió/AL. Para tanto, nossa amostra é constituída de dados obtidos por meio de entrevistas realizadas entre março e julho de 2016, com 52 informantes nascidos, criados e residentes na cidade de Maceió, entre a faixa etária de 18-38 anos e que possuem ou estão cursando o ensino superior completo. O instrumento utilizado para obter os dados foi um questionário composto por seis questões abertas e seis questões fechadas, adaptadas de Brustolin (2009) e Freitag (2016b), que tinham como objetivo aferir o que pensam os falantes maceioenses sobre a representação da primeira pessoa do plural.

\section{Análise e discussão dos dados}

Os resultados de pesquisas sociolinguísticas sobre a variação da primeira pessoa do plural na posição de sujeito na cidade de Maceió apontam que, na língua falada, a gente é o pronome preferido. Se o critério de frequência de uso corrobora os dados sociolinguísticos de que essa variação, nas variedades brasileiras, caminha para uma mudança linguística, com a implementação do pronome inovador, as atitudes dos falantes maceioenses caminham em direção contrária, tendo em vista que $54 \%$ dos falantes não só acreditam usar mais o pronome nós, como também $62 \%$ julgam melhor o seu uso, conforme observamos nos gráficos 7 e 8 . 
Gráfico 7: Resultado das respostas à questão 1

Quando você está conversando, você fala mais o pronome nós ou o pronome a gente?

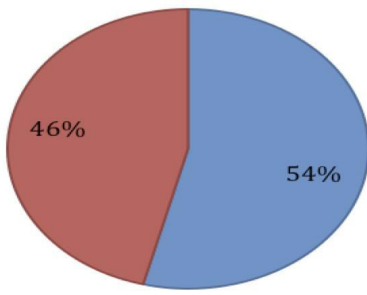

Fonte: elaborado pela autora

Gráfico 8: Resultado das respostas à questão 2

Qual dessas formas você acha melhor?

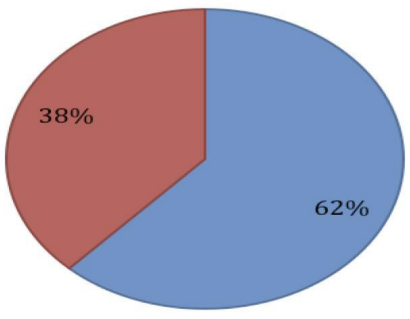

$\square$ nós

$\square$ a gente

Fonte: elaborado pela autora

Em relação à questão um - quando você está conversando, você fala mais o pronome nós ou o pronome a gente? - verificamos que os falantes pensam utilizar mais o pronome nós, apresentando um percentual de $54 \%$ versus $46 \%$ daqueles que acreditam usar mais o pronome a gente, o que nos mostra que as crenças dos falantes vão na direção contrária ao comportamento linguístico da comunidade. Quanto à questão dois - qual dessas formas você acha melhor? - $62 \%$ preferem o pronome nós, como em nós estudamos muito, contra $38 \%$ que dizem ser o uso de a gente melhor na língua falada, como em a gente estuda muito. 
Esses dados corroboram os achados apresentados por Freitag (2016a). A autora não só mostra que a avaliação social da variação nós e a gente na posição de sujeito caminha na direção contrária ao comportamento linguístico dos falantes sergipanos, como também argumenta que "a atitude mensurada sugere que, na primeira pessoa do plural, a forma 'a gente' tem comportamento de marcador, na medida que os informantes [...] fazem uso de uma variante, mas julgam melhor e até mesmo acreditam que usam a outra, 'nós', que é abonada pelos instrumentos normativos" (FREITAG, 2016a, p. 52).

Ao analisarmos o porquê de os falantes maceioenses acharem melhor o uso de uma ou de outra forma pronominal, observarmos que a preferência pelo uso de a gente deve-se às seguintes justificativas: "escuto mais pessoas falando dessa forma", "acredito que seja por costume", "por ser informal", "por ser mais corriqueiro", "porque é mais popular", "não precisa conjugar o verbo na pessoa do plural", quanto à preferência ao uso de nós, temos as seguintes justificativas: "soa mais correto", "acho mais formal", porque está de acordo com a norma culta", "acho feio e desconexo usar o pronome a gente em certas situações".

Embora os estudos sociolinguísticos apontem que não há estigma no uso dessas formas pronominais nas variedades brasileiras, tendo em vista a alta frequência de uso do pronome inovador em diversos contextos linguísticos e extralinguísticos, essas respostas sugerem que os julgamentos dos falantes maceioenses mostram que a variação nós e a gente na posição de sujeito apresenta uma alta saliência social, o que parece indicar que tal variação está, de certa forma, no nível de consciência social do falante, sugerindo que a alternância nós e a gente é um fenômeno linguístico do tipo marcador, razoavelmente sensível a avaliação social.

Em relação à variação na concordância verbal com o pronome nós, verificamos, conforme os gráficos 9 e 10, que 94\% dos falantes não só acreditam usar mais a forma nós + $1 P P$, como também 96\% julgam melhor o uso dessa variante linguística. Em resposta à questão três - quando você está conversando, você fala mais nós estudamos ou nós estuda? obtivemos 94\% para a forma nós $+1 P P$ contra apenas 6\% para nós + $3 P S$, o que vai na mesma direção do comportamento linguístico da comunidade de fala, que apresenta, segundo Vitório (em preparação), percentuais de $96 \%$ de nós $+1 P P$ contra apenas $4 \%$ de nós $+3 P S$. 
Gráfico 9: Resultado das respostas à questão 3

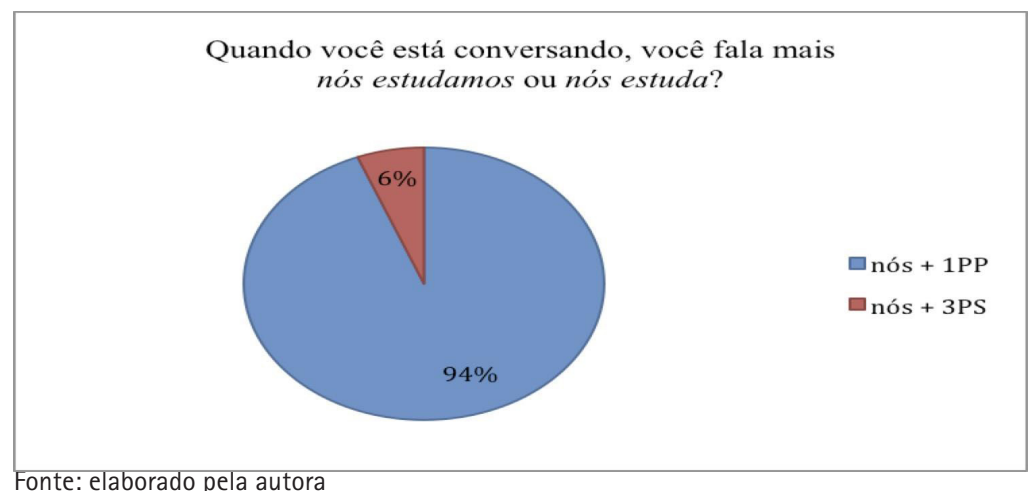

Fonte: elaborado pela autora

Gráfico 10: Resultado das respostas à questão 4

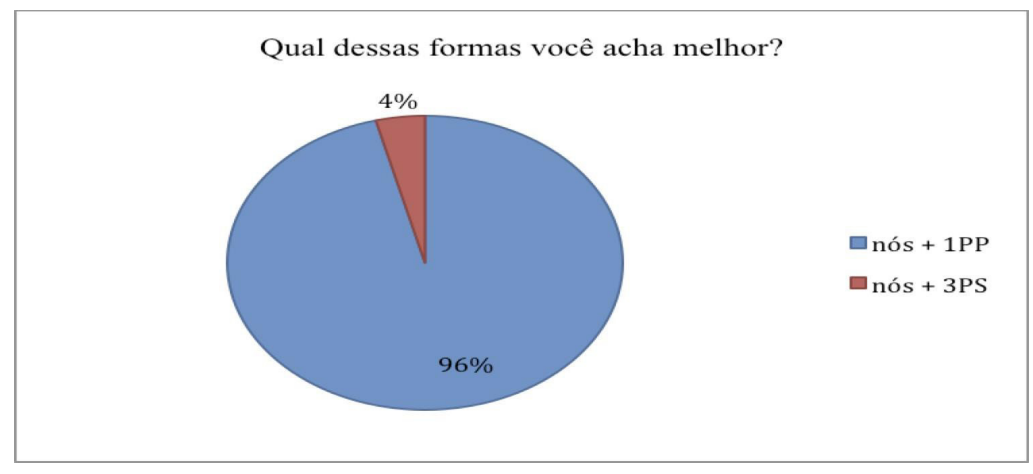

Fonte: elaborado pela autora

Quanto à avaliação linguística dessas variantes, verificamos que a resposta à questão quatro - qual dessas formas você acha melhor? gerou um percentual de $96 \%$ para nós $+1 P P$ e $4 \%$ para nós $+3 P S$. As justificativas dos falantes para a escolha de nós $+1 P P$ giram em torno da questão de ser a forma mais "correta" de uso da língua, como observamos nas seguintes respostas: "porque é a forma correta", "com plural, soa mais correto", "porque é a forma formal e a outra é a forma errada", "porque está de acordo com a norma culta". Os 4\% que acharam melhor nós $+3 P S$ argumentaram que "prefiro nós vai, porque sou mais jovem".

Em relação à variação da concordância verbal com a gente, verifi- 
camos, conforme os gráficos 11 e 12, que $84 \%$ dos falantes não só acreditam usar mais a gente $+3 P S$, corroborando o comportamento linguístico da comunidade, como também $82 \%$ julgam melhor o uso dessa variante. Ao analisarmos os dados obtidos para a questão cinco - quando você está conversando, você fala mais a gente estuda ou a gente estudamos? - verificamos que $84 \%$ acreditam usar a gente $+3 P S, 4 \%$ julgam usar a gente $+1 P P, 10 \%$ dizem que não usam nenhuma dessas variantes, pois utilizam apenas nós e $2 \%$ disseram não saber responder.

Gráfico 11: Resultado das respostas à questão 5

Quando você está conversando, você fala mais a gente estuda ou a gente estudamos?

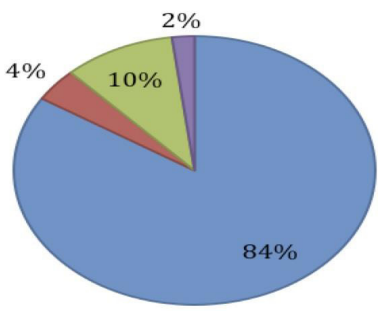

Gráfico 12: Resultado das respostas à questão 6

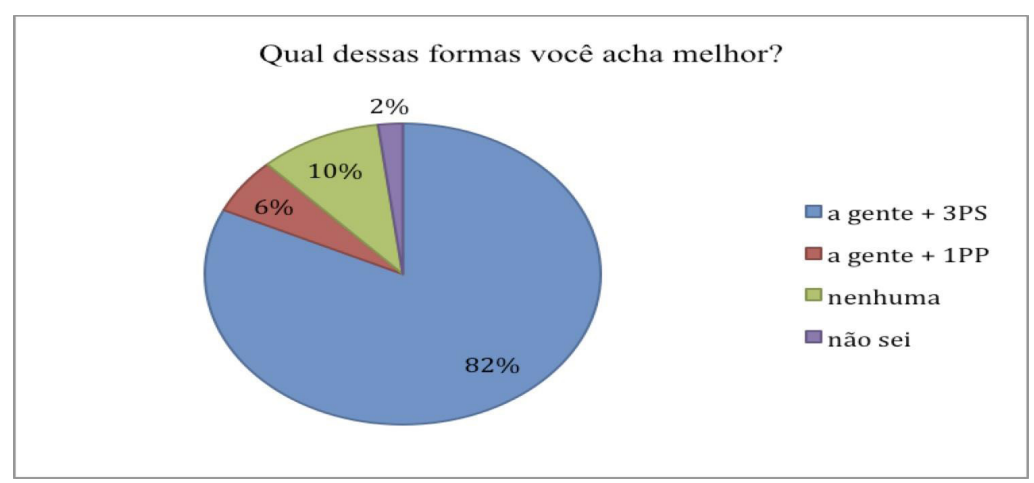

Fonte: elaborado pela autora 
No que diz respeito à questão seis - qual dessas formas você acha melhor? $-82 \%$ acreditam ser a gente $+3 P S$ e apenas $6 \%$ optaram por $a$ gente $+1 P P$, argumentando que "a primeira forma é a melhor, a segunda maneira soa errado e é um erro grosseiro de Português", "porque é a forma correta". Os que optaram por a gente $+1 P P$ argumentaram que "a gente parece com nós então o verbo vai para o plural". Também obtivemos um percentual de $10 \%$ que afirmam "nenhuma das duas, pois o correto é nós estudamos" e $2 \%$ afirmaram não saber responder, afirmando que "nunca reparei a forma que costumo pronunciar essas palavras".

Esses dados mostram que, tanto para a concordância com o pronome nós quanto para a concordância com o pronome a gente, os julgamentos dos falantes coadunam com o comportamento linguístico da comunidade de fala, apresentando parcas preferências pelo uso das variantes nós $+3 P S$ e a gente $+1 P P$. Os julgamentos dos falantes também sugerem que estamos diante de estereótipos linguísticos, ou seja, traços linguísticos socialmente marcados de forma consciente pelos falantes, principalmente a gente $+3 P S$, que, na comunidade de fala, é mais frequente entre os indivíduos de menor escolaridade e de maior faixa etária.

Em seguida, na questão sete - que forma você falaria e acha legal/boa? - observamos, conforme gráfico 13, percentuais de $40 \%$ para nós $+1 P P$ versus $12 \%$ para a gente $+3 P S$, também registramos um percentual de $40 \%$ para nós $+1 P P$ e a gente $+3 P S$, dados que parecem indicar que tanto nós $+1 P P$ quanto a gente $+3 P S$ são formas linguísticas que os maceioenses falam e acham legais/boas, mas com uma preferência maior para a realização do pronome nós com o verbo na primeira pessoa do plural, como nós moramos em Maceió, conforme procura justificar o informante - "o uso do pronome nós no lugar do a gente tem uma pronúncia melhor". Também obtivemos percentuais de $4 \%$ para nós $+3 P S, 2 \%$ para a gente $+1 P P$ e $2 \%$ para nós $+1 P P$ e a gente $+1 P P$. 
Gráfico 13: Resultado das respostas à questão 7

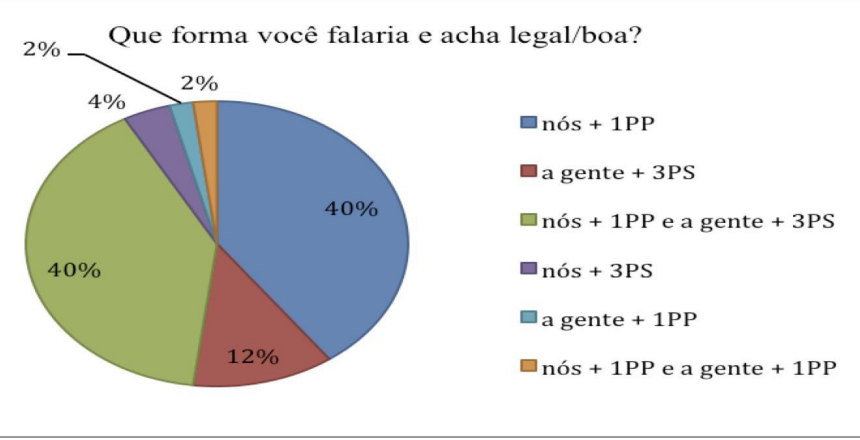

Fonte: elaborado pela autora

Na questão oito - que forma você falaria, mas acha ruim? - verificamos, conforme gráfico 14 , que $40 \%$ optam por a gente $+3 P S$, dado que corrobora, de fato, a afirmação de que os maceioenses julgam melhor o uso do pronome nós. No entanto, obtivemos também um percentual de $23 \%$ de nós $+1 P P$, que pertencem à fala dos que afirmam usar e achar melhor o uso de a gente. Também verificamos um percentual de $23 \%$ para nós $+3 P S$ e $8 \%$ para a gente $+1 P P$, o que parece indicar que, entre os falantes maceioenses, o uso de nós + 3PS, como nós mora em Maceió, é mais aceitável que o uso de a gente $+1 P P$, como a gente moramos em Maceió. Obtivemos também percentuais de $2 \%$ para nós $+3 P S$ e a gente $+3 P S, 2 \%$ para nós + $3 P S$, a gente $+3 P S$ e a gente $+1 P P$ e $2 \%$ para nós $+3 P S$ e a gente $+1 P P$.

\section{Gráfico 14: Resultado das respostas à questão 8}

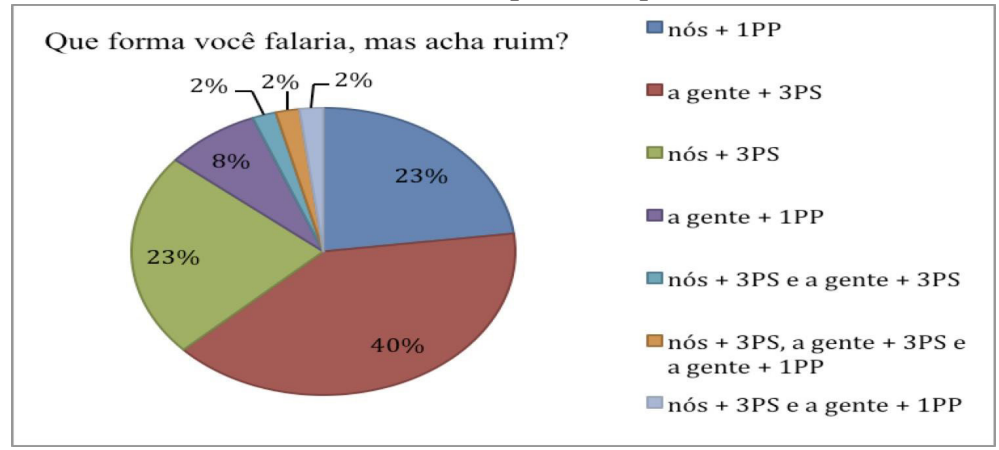

Fonte: elaborado pela autora 
Em seguida, na questão nove, perguntamos aos informantes: que forma você não falaria e acha ruim? De acordo com o gráfico 15 , verificamos que a gente + $1 P P$ e nós + 3PS são as variantes linguísticas escolhidas pelos informantes, com a gente $+1 P P$ apresentando um percentual maior de rejeição $-38 \%$ versus $23 \%$ para nós $+3 P S$. Essas variantes também receberam um percentual de $23 \%$, sugerindo, assim, que são formas linguísticas não aceitas pelos maceioenses. Também obtivemos percentuais de $8 \%$ para nós $+1 P P, 4 \%$ para a gente $+3 P S$, formas que pertencem à fala daqueles que preferem, respectivamente, o uso dos pronomes $a$ gente e nós, e $4 \%$ para nós $+3 P S$, a gente $+3 P S$ e a gente $+1 P P$.

Gráfico 15: Resultado das respostas à questão 9

Que forma você não falaria e acha ruim?

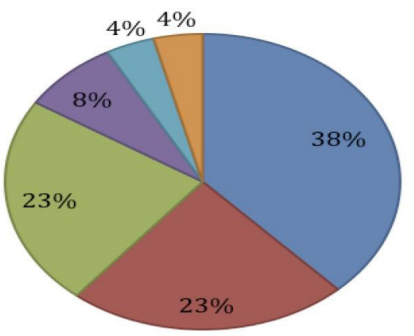

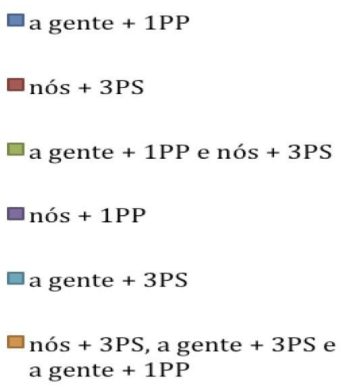

Fonte: elaborado pela autora

Na questão dez - que forma você nunca falaria? - verificamos, conforme gráfico 16 , que tanto nós $+3 P S$ quanto a gente $+1 P P$ são as variantes selecionadas pelos maceioenses, apresentando, assim, os seguintes resultados $-42 \%$ para nós $+3 P S$ e a gente $+1 P P, 29 \%$ para nós $+3 P S$ e $25 \%$ para a gente $+1 P P$. Esses dados coadunam com o comportamento linguístico da comunidade de fala que apresenta parcas realizações dessas variantes $-4 \%$ de nós $+3 P S$ e $6 \%$ de a gente $+1 P P$ e confirmam que essas formas são vistas como traços linguísticos marcados socialmente. Também verificamos a escolha da variante a gente $+3 P S$, escolha que corrobora a crença de alguns informantes de que "acho feio usar o pronome a gente", "o uso do pronome nós soa mais correto", "nós estudamos é a forma correta". 
Gráfico 16: Resultado das respostas à questão 10

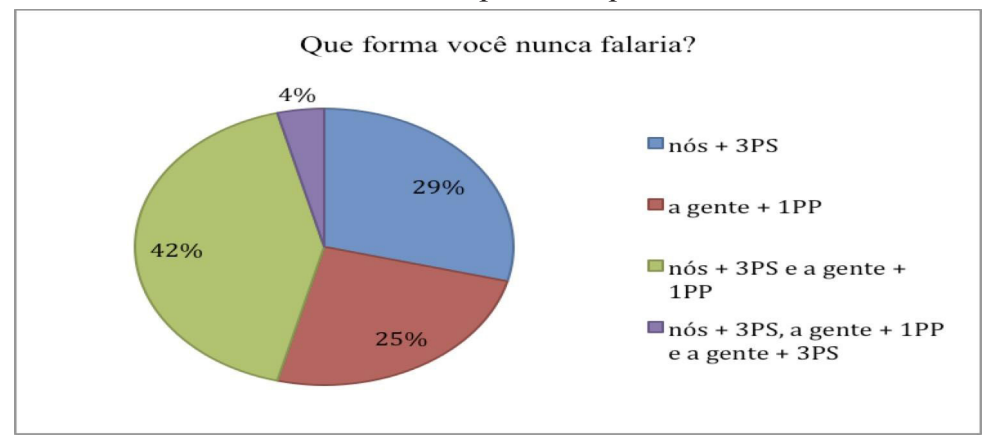

Fonte: elaborado pela autora

Nas questões onze e doze, perguntamos, respectivamente, que forma você falaria em uma situação formal e que forma você falaria em uma situação informal, e observamos, conforme gráfico 17, que, em uma situação formal, nós $+1 P P$ é a variante selecionada, apresentando um percentual de $90 \%$, ao passo que, em uma situação informal, conforme gráfico 18, a gente $+3 P S$ é a forma preferida, com um percentual de $56 \%$, elegendo, assim, o pronome nós, que é ensinado na escola, para falar em uma situação formal, o que confirma que, entre os maceioenses, o uso de nós e a gente comporta-se como um traço linguístico que recebe valoração social e estilística, caracterizando-se como um marcador linguístico.

Gráfico 17: Resultado das respostas à questão 11

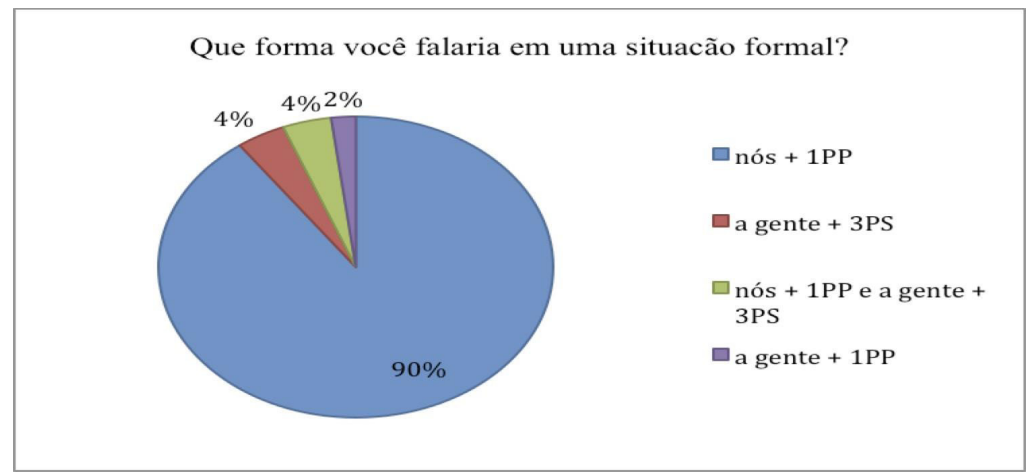

Fonte: elaborado pela autora 
Gráfico 18: Resultado das respostas à questão 12

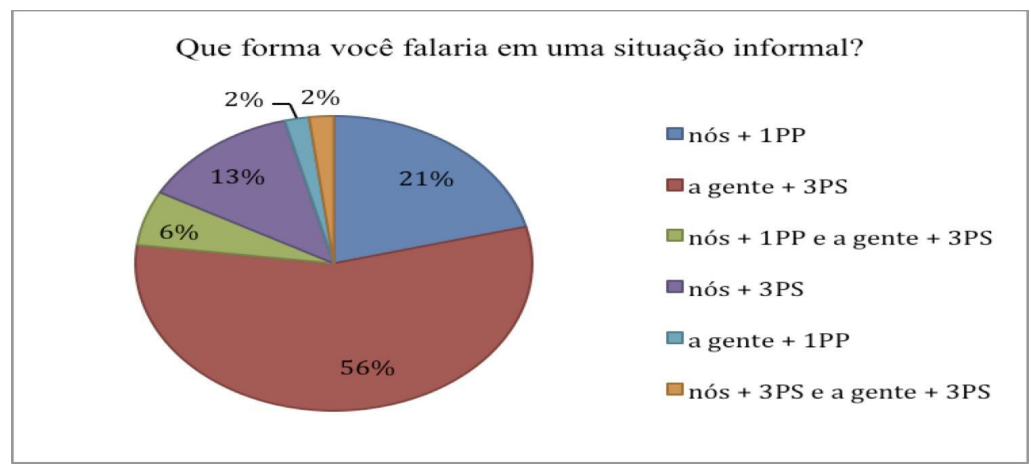

Fonte: elaborado pela autora

Em uma situação formal, também obtivemos percentuais de $4 \%$ para a gente $+3 P S, 4 \%$ para nós $+1 P P$ e a gente $+3 P S$ e $2 \%$ para a gente $+1 P P$. Em relação à realização de a gente $+1 P P$, os $2 \%$ representam a fala daqueles que julgam que a gente parece com nós, logo deve apresentar o verbo na 1PP. Vitório (2016c) mostra que, na escrita escolar, essa variante apresenta um percentual de uso maior $-62 \%$ contra $38 \%$ de a gente $+3 P S$, o que poderia ser um indício de que, na fala maceioense, seu uso poderia ter um significado social distinto, uma vez que o ambiente escolar tenta representar a forma linguística pertencente ao que seja culto em uma comunidade, no entanto, nossos dados sugerem que a gente $+1 P P$ é uma variante estigmatizada, ou seja, é uma forma linguística que recebe uma valoração social negativa.

Nossos dados também mostram que, em uma situação informal, além da preferência pelo uso de a gente $+3 P S$, registramos um percentual de $21 \%$ para nós $+1 P P$ e $6 \%$ para nós $+1 P P$ e a gente $+3 P S$. Em relação ao uso de nós $+3 P S$ e a gente $+1 P P$, verificamos, respectivamente, percentuais de $13 \%$ e $2 \%$, dados que confirmam que, apesar de serem avaliados como um traço linguístico fortemente sensível à avaliação social, entre os maceioenses, o uso de nós + 3PS, como nós mora em Maceió, é mais aceitável que o uso de a gente $+1 P P$, como a gente moramos em Maceió, em uma situação informal de uso da língua.

Ao perguntarmos a um falante maceioense você acha melhor nós mora em Maceió ou a gente moramos em Maceió, obtivemos como resposta "eu acho menos ruim nós mora em Maceió porque parece que a 
pessoa só erra depois entendeu", o que nos mostra não só a preferência pelo uso de nós, como também que o uso da forma nós $+3 P S$ é menos ruim que o uso de a gente $+1 P P$. Esses dados revelam que os julgamentos dos falantes maceioenses sobre o uso de nós e a gente são fortemente dependentes dos padrões de concordância verbal estabelecidos com esses pronomes, com as variantes nós $+1 P P$ e a gente $+3 P S$ sendo as formas boas, mas com uma preferência pelo uso de nós $+1 P P$, e as formas nós $+3 P S$ e a gente $+1 P P$ sendo as variantes rechaçadas, mas com uma leve aceitação de nós $+3 P S$.

\section{Considerações finais}

Tomando por base o problema da avaliação linguística (LABOV, 1972), que diz respeito ao valor social que os falantes atribuem às variantes linguísticas, sendo, portanto, um dos fatores que afetam o percurso da variação e da mudança, pois uma avaliação positiva ou negativa pode impulsionar ou refrear um processo de mudança, procuramos, neste trabalho, mensurar as reações subjetivas dos falantes maceioenses em relação a dois fenômenos linguísticos variáveis, a saber, a alternância pronominal nós e a gente na posição do sujeito e a concordância verbal estabelecida com essas formas pronominais.

Em relação à variação nós e $a$ gente na posição de sujeito, verificamos que as crenças e atitudes linguísticas dos falantes maceioenses não coadunam com o comportamento linguístico da comunidade, tendo em vista que, na cidade de Maceió, a gente é o pronome preferido para a referência à primeira pessoa do plural, mas os falantes não só acreditam usar o pronome nós, como também julgam melhor o seu uso, restringindo o uso de a gente a situações menos formais, o que sugere que, do ponto de vista da avaliação social, tal variação é um fenômeno linguístico do tipo marcador, razoavelmente sensível a avaliação social e que tal avaliação é fortemente dependente da concordância estabelecida com esses pronomes.

No que diz respeito à concordância verbal estabelecida com essas formas pronominais, verificamos que as crenças e atitudes linguísticas dos maceioenses coadunam com o comportamento linguístico da comunidade de fala, tendo em vista que nós $+1 P P$ e a gente $+3 P S$ são as variantes preferidas pelos falantes. Os dados também mostram que tanto a variação na concordância com o pronome nós quanto a variação na concordância com o pronome a gente constituem fenômenos linguísticos do 
tipo estereótipo, fortemente sensíveis a avaliação social, com as variantes nós $+3 P S$ e a gente $+1 P P$ sendo as formas que os falantes não usariam e acham ruins. No entanto, os dados também sugerem que o uso de nós + $3 P S$ é mais aceitável que o uso de a gente $+1 P P$.

\section{LINGUISTIC BELIEFS AND ATTITUDES OF THE USE}

\section{ABSTRACT}

Given that the way in which linguistic forms are evaluated - positive or negatively - can speed or stop a change in the language, we focus, in this work, in in the evaluation problem (LABOV, 1972), with the intention of measuring the subjective norms of the maceioenses speakers in relation to the pronominal alternation nós and $a$ gente and the verbal agreement related to these pronominal forms. For this propose, we resort the theoretical and methodological assumptions of Theory of Language Variation and Change and we used a sample constituted of 52 interviews of maceioenses speakers. According to the data analyzed, we verified that, in relation to the pronominal alternation, the linguistic beliefs and attitudes of the speakers do not correspond to the linguistic behavior of the community, suggesting that such alternation is a linguistic phenomena of the marker type, and, as far as to verbal agreement, we find that the linguistic beliefs and attitudes of the speakers move in the same direction as the linguistic behavior of the community, suggesting that both agreement with nós and agreement with a gente are phenomena of the stereotype type, with a greater acceptance of the use of the variant nós $+3 P S$.

KEYWORDS: Nós and a gente. Pronominal interchange. Verbal agreement. Social evaluation. 


\section{REFERÊNCIAS}

BOTASSINI, J. A importância dos estudos de crenças e atitudes para a Sociolinguística. Signum: Estudos da Linguagem, Londrina, n. 18/1, p. 102-131, jun. 2015.

BRANDÃO, S. Variação e o estatuto de variedades do português. Diadorim, Rio de Janeiro, Especial, p. 83-104, 2016.

BRUSTOLIN, A. Itinerário do uso e variação de nós e a gente em textos escritos e orais de alunos do ensino fundamental da rede pública de Florianópolis. Dissertação (Mestrado do Programa de Pós-Graduação em Linguística). Universidade Federal de Santa Catarina, 2009.

CARMO, S. A variação na concordância verbal com a primeira pessoa do plural em comunidades rurais do semiárido baiano. 2016. Dissertação (Mestrado em Estudos Linguísticos) - Universidade Estadual de Feira de Santana, 2016.

COELHO, I.; GORSKI, E.; MAY, G.; SOUZA, C. Sociolinguística. Florianópolis: LLV/CCE/UFSC, 2010.

CYRANKA, L. Atitudes linguísticas de alunos de escolas publicas de Juiz de Fora - MG. Tese (Doutorado em Estudos Linguísticos) - Universidade Federal Fluminense, Niteroi, 2007.

FREITAG, R. A gente só fala nós. In: Workshop Pronomes: morfossintaxe, semântica e processamento, 2016a, Salvador. Cadernos de resumos. Salvador: UFBA, $2016 \mathrm{a}$.

FREITAG, R. Uso, crença e atitudes na variação na primeira pessoa do plural no Português Brasileiro. D.E.L.T.A., 32, p. 889-917, 2016 b.

FREITAG, R.; SANTANA, C.; ANDRADE, T.; SOUSA, V. Avaliação e variação linguística: estereótipos, marcadores e indicadores em uma comunidade escolar. In: FRAITAG, R.; SEVERO, C,; GORSKI, E. (orgs). Sociolinguística e politica linguística: olhares contemporâneos. Editora Edgar Blucher Ltda: São Paulo, 2016.

KAUFMANN, G. Atitudes na sociolinguística: aspectos teóricos e metodológicos. In: RASO, T.; MELLO, H.; ALTENHONFEN, C. (orgs.) Os contatos linguísticos no Brasil. Belo Horizonte: Editora UFMG, 2011.

LABOV, W. Sociolinguistics patterns. Philadelphia, University of Pensylvania Press, 1972.

LOPES, C. O quadro dos pronomes pessoais: descompasso entre pesquisa e ensino. Matraga, Rio de Janeiro, v. 19. N. 30, 2012. 
LÓPEZ MORALES, H. Sociolinguística. Madri: Gredos, 2004.

MOLLICA, C. Fundamentação teórica: conceituação e delimitação. In: MOLLICA, C.; BRAGA, L. (orgs). Introdução à Sociolinguística: o tratamento da variação. São Paulo: Contexto, 2004.

MORENO FERNÁNDES, F. Principios de sociolinguística y sociologia del linguaje. Barcelona: Ariel, 1998.

NARO, A.; GORSKY, E.; FERNANDES, E.. Change without change. Language Variation and Change, 11, p. 197-211, 1999.

RUBIO, C. Decisões metodológicas no estudo de fenômenos variáveis de primeira pessoa do plural. Anais do XVII Congreso Internacional Asociación de Lingüística y Filología de América Latina, 2014.

RUBIO, C.; GONÇALVES, S. A fala do interior paulista no cenário da Sociolinguística brasileira: panorama da concordância verbal e da alternância pronominal. Alfa, São Paulo, 56 (3), p. 1003-1034, 2012.

SANTOS, K. Estratégias de polidez e a variação nós vs. a gente na fala de discentes da Universidade Federal de Sergipe. Dissertacão (Mestrado em Letras). Centro de Educação e Ciências Humanas, Universidade Federal de Sergipe, 2014. VIANNA, J.; LOPES, C. A competição entre nós e a gente nas funções de complemento e adjunto: desvendando outras portas de entrada para o pronome inovador. Caligrama, Belo Horizonte, v. 17, n. 2, p. 137-161, 2012.

VIANNA, J.; LOPES, C.. Variação dos pronomes "nós" e "a gente". In. MARTINS, M.; ABRAÇADO, J. Mapeamento sociolinguístico do português brasileiro. São Paulo: Contexto, 2015.

VITÓRIO, E. A variação nós e a gente na posição de sujieto na fala de crianças da cidade de Maceió/AL. Revista (Con)textos Linguísticos, v. 9, n.14, p. 126-141, $2015 \mathrm{a}$.

VITÓRIO, E. Variação nós e a gente na posição de sujieto na escrita escolar. Letras e Letras, Uberlândia, vol. 31/2, jul/dez, 2015 b.

VITÓRIO, E. Variação nós e a gente na fala culta da cidade de Maceió/AL. Interdisciplinar, Ano XI, v. 24, jan/abr, 2016a.

VITÓRIO, E. A realização dos pronomes nós e a gente nas funções de sujeito, complemento e adjunto na cidade de Maceió/AL. In: XXVI Jornada do Gelne, 2016, Recife. Rumo aos quarenta anos: livro de Resumos da XXVI Jornada do Gelne. Recife: Pipa Comunicação, v. 1. p. 849, 2016 b.

VITÓRIO, E. Variação linguística e ensino de Língua Portuguesa: aspectos inovadores na escrita escolar. Revista Língua e Letras, v. 17, n. 35, $2016 \mathrm{c}$. 
VITÓRIO, E. Concordância verbal, variação e avaliação: um estudo sobre nós e a gente na fala maceioense. (em preparação)

WEINREICH; U.; LABOV, L.; HERZOG, M. Fundamentos empíricos para uma teoria da mudança linguística. São Paulo: Parábola Editorial, 2006.

ZILLES, A. O que a fala e a escrita nos dizem sobre a avaliação social do uso de a gente? Letras de Hoje. Porto Alegre, v. 42, n. 2, p. 27-44, jun. 2007.

ZILLES, A.; MAYA, L.; SILVA, K. A concordância verbal com a $1^{\text {a }}$ pessoa do plural em Panambi e Porto Alegre. Organon, v. 14, n. 28-29, p. 195-219, 2000.

Recebido em: 09/01/2017

Aceito em: 11/06/2017 